\title{
Enteropatógenos predominantes en diarreas agudas y variables asociadas en niños atendidos en el Hospital Regional Lambayeque, Perú
}

\author{
Jhonatan Ipanaque-Chozo ${ }^{1, a}$, Eberth Seclen-Bernabe ${ }^{1, a}$, Olinda Bustamante-Canelo ${ }^{2, a, b}$, Franklin-Rómulo Aguilar-Gamboa ${ }^{3, a}$, \\ Katya Mera-Villasis ${ }^{3, a, b}$, Martha Vergara-Espinoza ${ }^{1, a, c}$, Heber Silva-Díaz,a,c
}

\section{RESUMEN}

Objetivo: Determinar el tipo y frecuencia de enteropatógenos predominantes en diarreas agudas y sus características asociadas en niños atendidos en el Hospital Regional Lambayeque (HRL) - Perú.

Materiales y métodos: Se realizó un estudio analítico transversal entre marzo y mayo del 2015 en 70 muestras fecales. Las muestras se estudiaron mediante coprocultivo e inmunocromatografía para la detección de bacterias y virus enteropatógenos respectivamente. Mientras que los enteroparásitos se buscaron mediante examen microscópico directo, tinción de Kinyoun y ELISA para coproantígenos (Entamoeba histolytica, Giardia lamblia y Cryptosporidium spp.). Asimismo se realizó conteo de leucocitos y pruebas químicas (Benedict, Thevenon y Sudan III) para el estudio funcional de la enfermedad diarreica.

Resultados: En el 48,6\% de muestras se detectó la etiología infecciosa de la diarrea, siendo predominante la causa parasitaria $(25,8 \%)$, seguida de la bacteriana $(17,1 \%)$ y viral $(5,8 \%)$. Los enteropatógenos más frecuentes fueron $\mathrm{G}$. lamblia $(18,6 \%)$ y Salmonella Enteritidis (10,0\%). Se observó asociación entre la cantidad de leucocitos mayor a 100 con la etiología bacteriana $(p=0,027)$, mientras que un número menor de 10 por campo $(p=0,002)$ y el Sudan III positivo $(p=0,003)$ con la etiología parasitaria.

Conclusiones: En más de la mitad de muestras $(51,4 \%)$ no se demostró etiología infecciosa de la diarrea, mientras que Giardia lamblia fue la más frecuente causa de diarrea en la población estudiada. No obstante, es necesaria la implementación de técnicas más sensibles y específicas para la detección de un rango mayor de enteropatógenos con el que se mejore el diagnóstico y tratamiento de la enfermedad.

Palabras clave: Diarrea infantil; diarrea infecciosa; giardia lamblia; salmonella enteritidis.

\section{Predominant enteropathogens in acute diarrhea and associated variables in children at the Lambayeque Regional Hospital, Peru}

ABSTRACT

Objective: To determine the type and frequency of predominant enteropathogens in acute diarrhea and their associated characteristics in children treated at Hospital Regional Lambayeque (HRL) - Peru.

Materials and methods: A cross-sectional analytical study was carried out in 70 fecal samples between March and May 2015. These samples were studied by coproculture and immunochromatography for the detection of enteropathogenic bacteria and viruses, respectively, while enteroparasites were sought by direct microscopic examination, Kinyoun staining method and ELISA for the detection of coproantigens (Entamoeba histolytica, Giardia lamblia and Cryptosporidium spp). Leukocyte count and chemical tests (Benedict, Thevenon and Sudan III) were also performed for the functional study of the diarrheal disease.

Results: In $48.6 \%$ of the samples, the infectious etiology of diarrhea was detected, prevailing the parasitic cause (25.8\%), followed by the bacterial (17.1\%) and viral (5.8\%) ones. The most common enteropathogens were G. lamblia $(18.6 \%)$ and Salmonella enteritidis (10.0\%). An association between greater than 100 fecal leukocytes per field and the bacterial etiology $(p=0.027)$ was observed, while less than 10 fecal leukocytes per field $(p=0.002)$ and a positive Sudam III test $(p=0.003)$ were associated with the parasitic etiology.

Conclusions: In more than half of the samples (51.4\%) the infectious etiology of diarrhea could not be proven, whereas Giardia lamblia was the most frequent cause of diarrhea in the studied population. However, it is necessary to implement more sensitive and specific techniques for the detection of a greater range of enteropathogens with which to improve the diagnosis and treatment of the disease

Keywords: Infantile diarrhea; infectious diarrhea; giardia lamblia; salmonella enteritidis.

1. Facultad de Ciencias Biológicas, Universidad Nacional Pedro Ruíz Gallo. Lambayeque, Perú.

2. Laboratorio de Bacteriología, Hospital Regional Lambayeque. Lambayeque, Perú.

3. Laboratorio de inmunología y Virología, Hospital Regional Lambayeque. Lambayeque, Perú.

4. Laboratorio de Parasitología-Metaxénicas y Zoonosis, Hospital Regional Lambayeque. Lambayeque, Perú.

a. Biólogo Microbiólogo.

b. Maestro en Ciencias.

c. Doctor en ciencias. 
Heber Silva-Díaz, Olinda Bustamante-Canelo, Franklin-Rómulo Aguilar-Gamboa, Katya Mera-Villasis, Jhonatan Ipanaque-Chozo, Eberth Seclen-Bernabe, Martha Vergara-Espinoza

\section{INTRODUCCIÓN}

La diarrea aguda infecciosa (DAI) es una alteración del movimiento intestinal, con incremento del contenido de agua, volumen o frecuencia de las evacuaciones, y suele ser ocasionado por diversos organismos bacterianos, parasitarios o virales ${ }^{(1,2)}$. Los niños menores de tres años pueden presentar en promedio tres episodios de diarrea al año, lo cual los priva de nutrientes necesarios para su crecimiento ${ }^{(3,4)}$. Los patógenos bacterianos más importantes incluyen a Aeromonas spp., Campylobacter spp. Escherichia coli diarreogénica, Salmonella spp., Shigella spp., Vibrio cholerae y Yersinia $s p p^{(5)}$.

La DAl continúa siendo una las principales causas de morbilidad y mortalidad en el mundo ${ }^{(6,7)}$. Esto se da principalmente en niños donde pese a las mejoras en el manejo y prevención, sigue siendo la tercera causa de muerte en menores de cinco años ${ }^{(8)}$. La enfermedad se ve asociada a las bajas condiciones socioeconómicas y deficiente saneamiento ambiental ${ }^{(9)}$.

Los mecanismos de acción utilizados por los enteropatógenos son diversos, los virus, bacterias enterotoxigénicas y parásitos inducen una mínima respuesta inflamatoria. Mientras que en infecciones por bacterias enteroinvasivas y algunas parasitarias se observa una respuesta inflamatoria más intensa, evidenciado por leucocitos en heces ${ }^{(10)}$. La detección de estos patógenos pueden realizarse mediante examen directo, cultivos, serología, enzimoinmuno ensayo directo o utilizando técnicas moleculares ${ }^{(11-14)}$. Asimismo, el 2016 el Ministerio de Salud (MINSA) señaló que en la región Lambayeque fueron reportados 1010 casos de DA en niños, lo cual disminuyó en un $59.8 \%$ a comparación al reporte del año $2015^{(15)}$. Actualmente el 30\% de la etiología diarreica es desconocida, aun usando técnicas complejas y sensibles para su detección ${ }^{(16)}$. En la Región Lambayeque y en muchas otras regiones del Perú, se desconoce la etiología de la enfermedad diarreica infantil, razón por la cual en la presente investigación se determinó el tipo y frecuencia de los enteropatógenos predominantes en diarreas agudas y sus características asociadas, en niños menores de 10 años atendidos en el Hospital Regional Lambayeque (HRL). Chiclayo, Perú.

\section{MATERIALES Y MÉTODOS}

\section{Diseño y área de estudio}

Se realizó un estudio transversal analítico, basado en población hospitalaria, entre los meses de marzo a mayo del 2015 en el HRL. Chiclayo, Perú.

\section{Población y muestra}

La población estuvo constituida por niños menores de 10 años con diagnóstico de diarrea aguda atendidos en los servicios de consultorio externo, pediatría y emergencia del HRL. Se incluyeron a los pacientes que tuvieron solicitud de examen coproparasitológico. El tamaño de muestra fue calculado en base a una proporción esperada de $17.26 \% 9$, un nivel de confianza del $95 \%$ y error de 0,9 . El diseño de muestreo fue sistemático.

\section{Procedimientos}

Las muestras fueron recolectadas siguiendo las recomendaciones del Manual de procedimientos para el diagnóstico de las parasitosis humanas ${ }^{(17)}$, luego identificadas con un código numérico seriado y enviadas a los laboratorios de Bacteriología, Inmuno-virología y Parasitología para la búsqueda de los enteropatógenos bacterianos, virales y parasitarios respectivamente. La muestra destinada al examen bacteriológico se conservó en medio de transporte Cary Blair.

Los enteropatógenos bacterianos fueron detectados mediante coprocultivos específicos para cada agente e identificados mediante su comportamiento fisiológico en medios diferenciales ${ }^{(18-20)}$. La identificación serológica de Salmonella spp., Shigella spp. y patotipos de E. coli (enteropatógena, enteroinvasiva, enterohemorrágica 0157:H7 y enteroagregativa) se realizó mediante test de aglutinación en lámina usando antisueros específicos marca "PROBAC DO BRASIL" contra antígenos flagelares y somáticos de las bacterias. El procedimiento siguió las recomendaciones del fabricante. Campylobacter sp., se detectó mediante coprocultivo en agar sangre mediante el método de filtración previamente descrito ${ }^{(21)}$.

Los parásitos fueron detectados mediante examen directo microscópico (EMD), tinción Kinyoun para coccidios ${ }^{(17)}$ y ELISA coproantígenos en Entamoeba histolytica, Giardia lamblia y Cryptosporidium spp. (r-Biopharm). Por otro lado, la detección de los virus Rotavirus y Adenovirus se realizó con la técnica de inmunocromatografía ( $r$-Biopharm). Los procedimientos que usaron kit comercial siguieron las recomendaciones del fabricante.

Por último se realizó el análisis coprológico funcional con el fin de evaluar los leucocitos, sangre oculta, azúcares reductores y grasas mediante los métodos de azul de metileno10, Thevenon (22), Bénedict ${ }^{(23)}$ y Sudan III (24) respectivamente.

\section{Análisis de datos}

Se calcularon frecuencias absolutas y relativas de los enteropatógenos. Asimismo se realizaron las pruebas de Chi cuadrado, exacta de Fisher y OR con el fin de buscar asociación entre el tipo de enteropatógeno con las características macroscópicas, inflamatorias y químicas de las heces, edad, género y procedencia. Se consideró un nivel de confianza al 95\% y un valor significativo de 
$\mathrm{p}<0.05$. Se utilizaron los programas informáticos SPSS 22.0 y e Infostat/E.

\section{Consideraciones éticas}

El estudio fue revisado y aprobado por el comité de ética del HRL, para el cual se solicitó la autorización correspondiente.

\section{RESULTADOS}

Se estudiaron 70 muestras de heces diarreicas procedentes de pacientes menores de 10 años, de los cuales en el $48,6 \%$ $(34 / 70)$ se demostró el agente etiológico. La mediana de edad fue de un año (rango intercuartílico de 0 a 3 años). En un alto porcentaje de las muestras no se detectó agente etiológico; el grupo más predominante fue el tipo parasitario, seguido del bacteriano y viral (Figura 1).

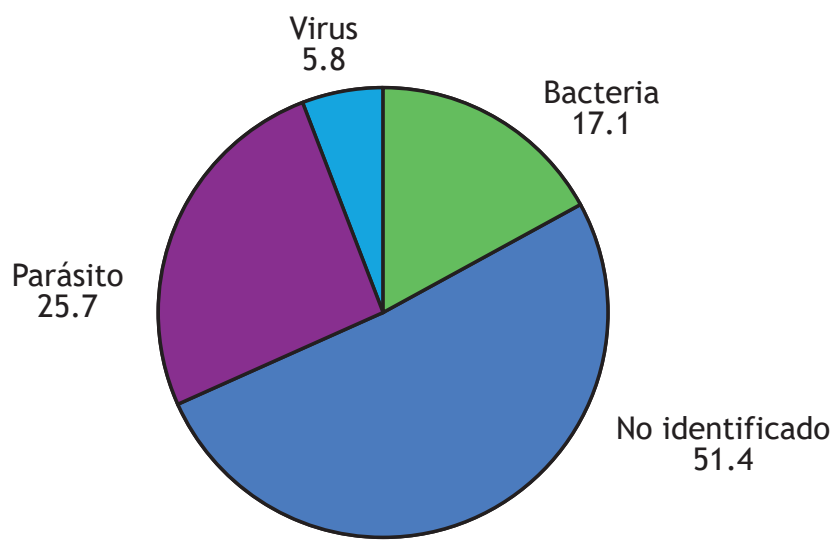

Figura 1. Etiología predominante de la diarrea aguda Infecciosa en niños atendidos en el HRL - Perú

En un alto porcentaje de las muestras no se detectó agente etiológico, mientras que en las que se detectó, Giardia lamblia fue el enteropatógeno más frecuente (18,6\%), seguido de Salmonella Enteritidis (10,0\%) (Tabla 1).

Tabla 1. Frecuencia y distribución de los enteropatógenos predominantes de la diarrea aguda infecciosa en niños atendidos en el Hospital Regional Lambayeque, Perú

$\begin{array}{lcc}\text { Enteropatógeno } & \mathrm{N}=70 & (\%) \\ \text { Parásitos } & 13 & (18,6) \\ \text { Giardia lamblia } & 3 & (4,3) \\ \text { Blastocystis hominis } & 2 & (2,8) \\ \text { Cryptosporidium spp. } & & \\ \text { Bacterias } & 7 & (10,0) \\ \text { Salmonella Enteritidis } & 3 & (4,3) \\ \text { Campylobacter sp. } & 1 & (1,4) \\ \text { Escherichia coli Enteropatógena (EPEC) } & 1 & (1,4) \\ \text { Shigella sp. } & & \\ \text { Virus } & 2 & (2,9) \\ \text { Ro tavirus } & 2 & (2,9) \\ \text { Adenovirus } & 34 & (48,6) \\ \text { TOTAL } & & \end{array}$

Fuente: Estudio "Enteropatógenos predominantes en diarreas agudas y variables asociadas, en niños atendidos en el Hospital Regional Lambayeque, Perú" 
Heber Silva-Díaz, Olinda Bustamante-Canelo, Franklin-Rómulo Aguilar-Gamboa, Katya Mera-Villasis, Jhonatan Ipanaque-Chozo, Eberth Seclen-Bernabe, Martha Vergara-Espinoza

La distribución de estos microorganismos y de los casos no identificados en relación al género, grupo etario, características físicas y químicas de las heces (Tabla 2). Se observó un predominio de consistencia blanda sobre las liquidas con un $66.7 \%$ en las muestras sin identificación etiológica. Asimismo, un alto porcentaje de las muestras presentaron resultados de sangre, Bénedict y Sudán III negativos, a la vez que hubo ausencia de reacción inflamatoria en la mayoría de muestras estudiadas.

Tabla 2. Características de las muestras con diarrea aguda infecciosa por enteropatógenos en el Hospital Regional Lambayeque, Perú

\begin{tabular}{|c|c|c|c|c|c|c|c|c|}
\hline \multirow[t]{2}{*}{ Variable } & \multicolumn{2}{|c|}{ Bacterias } & \multicolumn{2}{|c|}{ Virus } & \multicolumn{2}{|c|}{ Parásitos } & \multicolumn{2}{|c|}{ No identificado } \\
\hline & $\mathrm{N}$ & (\%) & $\mathrm{N}$ & (\%) & $\mathrm{N}$ & (\%) & $\mathrm{N}$ & (\%) \\
\hline \multicolumn{9}{|l|}{ Género } \\
\hline Masculino & 9 & $(75,0)$ & 3 & $(75,0)$ & 12 & $(66,7)$ & 18 & $(50,0)$ \\
\hline Femenino & 3 & $(25,0)$ & 1 & $(25,0)$ & 6 & $(33,3)$ & 18 & $(50,0)$ \\
\hline \multicolumn{9}{|l|}{ Grupo etario } \\
\hline $0-5$ & 11 & $(91,7)$ & 4 & $(100,0)$ & 14 & $(77,8)$ & 30 & $(83,3)$ \\
\hline $6-10$ & 1 & $(8,3)$ & 0 & $(0,0)$ & 4 & $(22,2)$ & 6 & $(16,7)$ \\
\hline \multicolumn{9}{|l|}{ Consistencia } \\
\hline Blanda & 5 & $(41,7)$ & 3 & $(75,0)$ & 14 & $(77,8)$ & 24 & $(66,7)$ \\
\hline Líquida & 7 & $(58,3)$ & 1 & $(25,0)$ & 4 & $(22,2)$ & 12 & $(33,3)$ \\
\hline \multicolumn{9}{|l|}{ Moco } \\
\hline Positivo & 11 & $(91,7)$ & 1 & $(25,0)$ & 10 & $(55,6)$ & 29 & $(80,6)$ \\
\hline Negativo & 1 & $(8,3)$ & 3 & $(75,0)$ & 8 & $(44,4)$ & 7 & $(19,4)$ \\
\hline \multicolumn{9}{|l|}{ Sangre } \\
\hline Positivo & 2 & $(16,7)$ & 0 & $(0,0)$ & 1 & $(5,6)$ & 4 & $(9,1)$ \\
\hline Negativo & 10 & $(83,3)$ & 4 & $(100,0)$ & 17 & $(94,4)$ & 32 & $(88,9)$ \\
\hline \multicolumn{9}{|l|}{ Leucocitos } \\
\hline $0-10$ & 3 & $(25,0)$ & 4 & $(100,0)$ & 17 & $(94,4)$ & 18 & $(50,00)$ \\
\hline $11-99$ & 5 & $(41,7)$ & 0 & $(0,0)$ & 1 & $(5,6)$ & 10 & $(27,8)$ \\
\hline 100 a más & 4 & $(33,3)$ & 00 & $(0,0)$ & 0 & $(0,00)$ & 8 & $(22,2)$ \\
\hline \multicolumn{9}{|l|}{ Thévenon } \\
\hline Positivo & 8 & $(66,7)$ & 2 & $(50,0)$ & 9 & $(50,0)$ & 13 & $(36,1)$ \\
\hline Negativo & 4 & $(33,3)$ & 2 & $(50,0)$ & 9 & $(50,0)$ & 23 & $(63,9)$ \\
\hline \multicolumn{9}{|l|}{ Bénedict } \\
\hline Positivo & 1 & $(14,3)$ & 2 & $(50,0)$ & 2 & $(11,1)$ & 13 & $(36,1)$ \\
\hline Negativo & 11 & $(85,7)$ & 2 & $(50,0)$ & 16 & $(88,9)$ & 23 & $(63,9)$ \\
\hline \multicolumn{9}{|l|}{ Sudan III } \\
\hline Positivo & 3 & $(8,3)$ & 0 & $(0,0)$ & 10 & $(55,6)$ & 6 & $(16,7)$ \\
\hline Negativo & 9 & $(91,7)$ & 4 & $(100,0)$ & 8 & $(44,4)$ & 30 & $(83,3)$ \\
\hline
\end{tabular}

Fuente: Estudio “Enteropatógenos predominantes en diarreas agudas y variables asociadas, en niños atendidos en el Hospital Regional Lambayeque, Perú”

El análisis bivariado mostró que las diarreicas de etiología bacteriana se asociaron con la mayor frecuencia de leucocitos en heces en un número mayor a 100 por campo $(p=0,027 ; O R=5,43 ; I C 95 \%=1,09-27,00)$; mientras que, las de etiología parasitaria con un número de leucocitos menor a 10 por campo $(p=0,002 ; O R=10,90 ; I C 95 \%=1,32-30,00)$ y con la mayor frecuencia de positividad en la prueba de Sudan III ( $p=0,003 ;$ OR=5,97; IC $95 \%=1,90-18,8)$. Las demás variables no mostraron asociación con las etiologías diarreicas (Tabla 3). 
Enteropatógenos predominantes en diarreas agudas y variables asociadas en niños

atendidos en el Hospital Regional Lambayeque, Perú

Tabla 3. Análisis bivariado de la diarrea aguda por enteropatógenos en niños atendidos en el Hospital Regional Lambayeque, Perú

\begin{tabular}{|c|c|c|c|c|c|c|c|c|c|}
\hline \multirow{2}{*}{ Variable } & \multicolumn{3}{|c|}{ EDA bacteriana } & \multicolumn{3}{|c|}{ EDA viral } & \multicolumn{3}{|c|}{ EDA parasitaria } \\
\hline & Positivos/total (\%) & OR (IC 95\%) & Valor $p$ & Positivos/total (\% & $\%$ OR (IC 95\%) & Valor $p$ & Positivos/total (\%) & OR (IC 95\%) & Valor $p$ \\
\hline \multicolumn{10}{|l|}{ Género } \\
\hline Masculino & $10 / 42(23,8)$ & $1,88(0,55-6,37)$ & 0,378 & $3 / 42(7,1)$ & $2,08(0,29-14,9)$ & 0,645 & $12 / 42(28,6)$ & $1,47(0,49-4,38)$ & 8) 0,584 \\
\hline Femenino & $4 / 28(14,3)$ & & & $1 / 28(3,6)$ & & & $6 / 28(21,4)$ & & \\
\hline \multicolumn{10}{|c|}{ Grupo etario } \\
\hline $0-5$ & $12 / 59(20,3)$ & $1,15(0,25-5,29)$ & 0,999 & $4 / 59(6,8)$ & SV & 0,61 & $14 / 59(23,7)$ & $1,84(0,50-6,81)$ & 1) 0,456 \\
\hline $6 \cdot 10$ & $2 / 9(18,18)$ & & & $0 / 11(0,0)$ & & & $4 / 11(36,4)$ & & \\
\hline \multicolumn{10}{|c|}{ Consistencia } \\
\hline Blanda & $6 / 46(13,0)$ & $3,33(1,03-10,75)$ & 0,061 & $3 / 46(6,5)$ & $1,60(0,22-11,59)$ & 0,999 & $14 / 46(30,4)$ & $2,19(0,66-7,22)$ & 2) 0,259 \\
\hline Líquida & $8 / 24(33,3)$ & & & $1 / 24(4,2)$ & & & $4 / 24(16,7)$ & & \\
\hline \multicolumn{10}{|l|}{ Moco } \\
\hline Positivo & $13 / 52(25,0)$ & $5,67(0,96-33,55)$ & 0,096 & $1 / 52(1,9)$ & $10,20(1,3925,01)$ & ) 0,049 & $10 / 52(19,2)$ & $3,36(1,09-10,39$ & 9) 0,058 \\
\hline Negativo & $1 / 18(5,6)$ & & & $3 / 18(16,7)$ & & & $8 / 18(44,4)$ & & \\
\hline \multicolumn{10}{|l|}{ Sangre } \\
\hline Positivo & $3 / 7(42,9)$ & $3,55(0,76-16,47)$ & 0,137 & $0 / 7(0,0)$ & SV & 0,999 & $1 / 7(14,3)$ & $2,22(0,35 \cdot 14,22$ & 2) 0,668 \\
\hline Negativo & $11 / 63(17,5)$ & & & $4 / 63(6,4)$ & & & $17 / 63(26,9)$ & & \\
\hline \multicolumn{10}{|c|}{ Leucocitos } \\
\hline $0-10$ & $4 / 42(9,5)$ & 1 & 0,027 & $4,42(9,5)$ & SV & 0,243 & $17 / 42(40,5)$ & $10,90(1,3230,00$ & 0) 0,002 \\
\hline $11 \cdot 99$ & $6 / 17(35,3)$ & $5,18(1,24-21,7)$ & & $0 / 11(0,0)$ & & & $1 / 17(5,9)$ & 1 & \\
\hline 100 a más & $4 / 11(36,4)$ & $5,43(1,09-27,00)$ & & $0 / 17(0,0)$ & & & $0 / 11(0,0)$ & SV & \\
\hline \multicolumn{10}{|l|}{ Thévenon } \\
\hline Positivo & $9 / 32(28,1)$ & $2,58(0,80-8,36)$ & 0,143 & $2 / 32(6,3)$ & $1,20(0,19-7,39)$ & 0,999 & $9 / 32(28,1)$ & $1,26(0,44-3,60)$ & 0) 0,786 \\
\hline Negativo & $5 / 38(13,2)$ & & & $2 / 38(5,3)$ & & & $9 / 38(23,7)$ & & \\
\hline \multicolumn{10}{|l|}{ Bénedict } \\
\hline Positivo & $2 / 18(11,1)$ & $2,40(0,55-10,48)$ & 0,331 & $2 / 18(11,1)$ & $3,13(0,50-19,66)$ & 0,566 & $2 / 18(11,1)$ & $3,56(0,83-15,18$ & 8) 0,126 \\
\hline Negativo & $12 / 52(23,1)$ & & & $2 / 52(3,9)$ & & & $16 / 52(30,8)$ & & \\
\hline \multicolumn{10}{|l|}{ Sudan III } \\
\hline Positivo & $4 / 19(21,1)$ & $1,09(0,31-3,81)$ & 0,999 & $0 / 19(0,0)$ & SV & 0,331 & $10 / 19(52,6)$ & $5,97(1,90-18,8)$ & 8) 0,003 \\
\hline Negativo & $10 / 51(19,6)$ & & & $4 / 51(7,8)$ & & & $8 / 51(15,7)$ & & \\
\hline
\end{tabular}

SV: Sin valor. Cálculo no factible por insuficiente data.

Fuente: Estudio “Enteropatógenos predominantes en diarreas agudas y variables asociadas, en niños atendidos en el Hospital Regional Lambayeque, Perú”

\section{DISCUSIÓN}

La diarrea es una enfermedad frecuente en infantes y niños, donde se presenta como una de las principales causas de malnutrición y elevados niveles de morbilidad y mortalidad, esto último principalmente en regiones del África y el sur de Asia ${ }^{(25)}$. En Latinoamérica todavía se presenta como una de las principales enfermedades que puede ocasionar hasta 100 muertes en niños al día (ver comunicado del BID 2009). Por ello, es muy importante mantener la vigilancia de estos eventos y conocer su frecuencia y etiología. El presente estudio encontró un $48,6 \%$ de casos con etiología infecciosa (parásitos $25,7 \%$, bacterias $17,1 \%$ y virus $5,8 \%$ ), lo que se correlaciona con otro estudio realizado en Latinoamérica, donde describen $27,3 \%, 5,4 \%$ y $12,7 \%$ de etiología parasitaria, bacteriana y viral respectivamente ${ }^{(6)}$. 
Heber Silva-Díaz, Olinda Bustamante-Canelo, Franklin-Rómulo Aguilar-Gamboa, Katya Mera-Villasis, Jhonatan Ipanaque-Chozo, Eberth Seclen-Bernabe, Martha Vergara-Espinoza

La etiología de la enfermedad diarreica aguda (EDA) proporciona al clínico un dato importante que repercute tanto en el tratamiento in situ que se otorgue al paciente como en la terapia empírica que se disponga en base a los registros históricos de este. En el presente estudio se encontró que en el $51,4 \%$ de muestras no se identificó agente etiológico, similar al $54,6 \%$ descrito en otro estudio ${ }^{(6)}$. Estos resultados con alta frecuencia de etiología no identificada podría deberse a que, en el diagnóstico microbiológico de enteropatógenos algunos patotipos de E. coli, Aeromonas spp. o enterovirus son identificados con mayor sensibilidad y especificidad por técnicas moleculares, que no fueron usadas aquí. Así mismo, no todas las enfermedades diarreicas agudas (EDA) son de etiología infecciosa, pudiendo ser también de origen fisiológico o por medicamentos. Sin embargo, el alto porcentaje de ausencia etiológica hallada en nuestro estudio es importante y debe motivar a mejorar los métodos de detección de otros enteropatógenos y promover estudios que aborden el tema de la enfermedad diarreica aguda (EDA) de origen no infeccioso.

En el presente estudio se demostró el predominio de G. lamblia como causante de diarrea en niños, resultado similar a otro estudio realizado en Perú ${ }^{(26)}$, donde además, considera a este protozoo parásito, endémico en la región Lambayeque. Estos hallazgos revelan la preocupante frecuencia de G. lamblia como el principal agente etiológico de enfermedad diarreica aguda (EDA) en nuestra región, lo que hace sugerir que ante cualquier episodio de diarrea se debería considerar un tamizaje de este parásito, no solo por técnicas parasitológicas clásicas sino especializadas (ELISA coproantígenos y moleculares).

Estudios realizados en América Latina demuestran la elevada frecuencia de la etiología bacteriana en las enfermedades diarreicas agudas (EDA), principalmente en niños $(1,27-29)$. En el presente estudio, se encontró que el $17,1 \%$ de los casos fueron producidos por bacterias, principalmente por Salmonella Enteritidis, lo cual concuerda con otro estudio que también reporta una alta frecuencia de esta bacteria en nuestra región (Gonzales et al 2011). Debido a que la principal vía de transmisión de Salmonella Enteritidis son los alimentos, esta bacteria es común causa de diarrea en niños alrededor del mundo (8). De hecho, los alimentos preparados con higiene deficiente pueden albergar la suficiente carga bacteriana para causar enfermedad. Esto sumado a la venta informal y ambulatoria de los mismos en los alrededores de los colegios en nuestro país, hacen que la frecuencia de estos casos sean comprensibles.

En cuanto a la etiología viral, este estudio revela una baja frecuencia de Rotavirus y Adenovirus entéricos (2,9\% en ambos casos). Estos resultados difieren de estudios previos en Lima y Brasil que reportan frecuencias mayores de Rotavirus y lo señalan como principal causa de gastroenteritis en lactantes ${ }^{(13,30)}$. Esta diferencia probablemente se debe a que el rango de edad de los pacientes en el presente estudio fue mayor en comparación a los estudios mencionados. Por otro lado la introducción de la vacuna contra Rotavirus ha disminuido el número de casos considerablemente en pacientes vacunados ${ }^{(8)}$. No obstante, en los últimos años se están presentando en nuestro país reportes de otros agentes virales como el Norovirus, que desde el 2014 han cobrado mayor protagonismo en las infecciones diarreicas ${ }^{(31)}$. Una limitación del presente estudio fue que no se consideró la búsqueda de Norovirus, debido a la poca disponibilidad en nuestro país del kit empleado para su detección.

En relación a la frecuencia de enteropatógenos según el grupo etario, el mayor índice de aislamiento correspondiente a niños de cero a cinco años $(84,29 \%)$, concuerda con estudios anteriores ${ }^{(1,6)}$. Este resultado es debido a que los niños en esta edad suelen estar más propensos a sufrir riesgo de contaminación al estar en contacto directo suelo, mascotas, alimentos contaminados, entre otros.

Los enteropatógenos tienen diversos mecanismos por los cuales inducen diarrea. Los virus y parásitos suelen producir diarrea acuosa de tipo osmótica mientras que las bacterias suelen producirlas con sangre y acompañadas frecuentemente con reacción inflamatoria ${ }^{(8)}$. Sin embargo, en el presente estudio se observó que el análisis coprológico funcional podría aportar información que complementa el estudio etiológico de la enfermedad diarreica aguda (EDA) y apoye el diagnóstico empírico de la misma. El presente estudio mostró que la presencia de leucocitos en heces en una cantidad mayor a 100 por campo (reacción inflamatoria positiva), se asoció a la diarrea de etiología bacteriana; mientras que, una cantidad menor de 10 por campo y la prueba de Sudan III positiva fue asociada a una diarrea de tipo parasitaria. Lo cual concuerda con datos reportados en un estudio realizado en Lima, Perú ${ }^{(10)}$, donde indican que un número elevado de leucocitos aumenta la probabilidad de obtener un coprocultivo positivo (EDA bacteriana) y la presencia de estas células en baja proporción disminuye dicha probabilidad.

En conclusión, casi la mitad de las diarreicas agudas en pacientes que asisten al HRL son de etiología desconocida y en aquellas que sí se detectó agente etiológico, G. lamblia y Salmonella Enteritidis fueron los enteropatógenos más frecuentes. Así mismo, el conteo de leucocitos y la prueba de sudan III resultan ser un importante apoyo al diagnóstico etiológico bacteriano y parasitario respectivamente.

\section{REFERENCIAS BIBLIOGRÁFICAS}

1. Cabrera-Gaytán, D. A., Maldonado-Burgos, M. A., RojasMendoza, T. \& Grajales-Muñiz, C. Enfermedad diarreica aguda en niños menores de cinco años de edad: aportaciones de los núcleos trazadores de vigilancia epidemiológica 2012-2013. Arch Inv Mat Inf. 2013;5(3):118-25.

2. Catherine A. Churgay MD, Hope Medical Clinic, Ypsilanti, Michigan Zahra Aftab, MD, St. Luke's Hospital/University of Toledo, Maumee, O. Gastroenteritis in Children: Part I. Diagnosis. 2012;85:1059-62.

3. Gonzales S, Bada M, Rojas G, Bernaola, A, Chavez B. Guía de práctica clínica sobre el diagnóstico y tratamiento de la diarrea aguda infecciosa en pediatría Perú-2011. 2011;31:258-77. 
4. Donizetti Rossi Castro, E. Cristina Braga Yassaka Germini, M. Enteropathogens Detected In a Daycare Center, Southeastern Brazil: Bacteria, Virus, And Parasite Research. Rev. Inst. Med. Trop. Sao Paulo. 2015;57:27-32.

5. Escalante E. Coinfecciones bacterianas causantes de enfermedad diarreica aguda, en el Instituto Nacional de Salud del Niño Bacterial coinfections causing acute diarrhea, at the Instituto Nacional. 2015, 76(4): 1-2.

6. Cermeño J, Hernández de Cuesta I, Camaripanoa M, Medina N, Guevara A, Hernández Rivero C. Etiología de diarrea aguda en niños menores de 5 años Ciudad Bolívar, Venezuela. 2008; 28: $55-60$.

7. Krumkamp R, Sarpong N, Schwarz N, Adelkofer J, Loag W, Eibach D, et al. Gastrointestinal Infections and Diarrheal Disease in Ghanaian Infants and Children: An Outpatient CaseControl Study.2015;9(3):1-14.

8. Riveros M, Ochoa T, Enteropatógenos de Importancia en Salud Pública. Rev Peru Med Exp Salud Publica . 2015;32(1), 157-64.

9. Giugno S, Oderiz S. Etiología bacteriana de la diarrea aguda en pacientes pediátricos. Acta Bioquímica Clínica Latinoam. 2010; 44(1): 63-70.

10. Yhuri N, Ugarte K, Huicho L. Leucocitos fecales en niños con diarrea aguda: ¿momento de reconsiderar la utilidad clínica de la prueba? Rev Gastroenterol Perú. 2011; 31(3): 216-23.

11. Ochoa T, Mercado E, Durand D, Rivera F, Mosquito S, Contreras C, et al.Frecuencia Y Patotipos De Escherichia coli Diarrogénica en niños peruanos con y sin diarrea. Revista Peruana de Medicina Experimental y Salud Pública 2011; 28(1); 13-20.

12. Al-Kubaisy W, Al-Talib H, Al-Khateeb A, Shanshal M. Intestinal Parasitic Diarrhea among Children in Baghdad - Iraq. Trop. Biomed. 2014;31(3): 499-506.

13. Guerra-Sanches F, Norberg A, Madeira-Olivera J, AguilarUriarte M, Covarrubias-Loayza E, Serra-Freire N. Rotavirosis en niños de la región de la Baixada Fluminense, Rio de Janeiro, Brasil. Rev. Medica Hered. 2013; 24(4): 277-80.

14. Bucher A, Rivara G, Briceño D, Huicho L. Uso de una Prueba Rápida de Rotavirus en la Prescripción de Antibióticos en Diarrea Aguda Pediátrica: Un Estudio Observacional, Aleatorizado y Controlado. Rev. Gastroenterol. 2012;32(1);11-5.

15. Dirección General de Epidemiología. Boletin epidemiologico (Lima - Perú). 2016: 27-41. Disponible en: http://www. dge.gob.pe/portal/docs/vigilancia/boletines/2016/02.pdf. (Accessed: 15th October 2016).

16. Luizaga $P$, Luizaga L, Jarro R. Incidencia de Enfermedades Diarreicas Agudas, 2010 (Enero-Junio), del Centro de Salud Lacma. Rev Cient Cienc Med.2010; 13(1): 9-10.

17. Beltran M, Tello R, Náquira. C. Manual de procedimientos de laboratorio para el diagnóstico de los parásitos intestinales del hombre. 2003: 1-89. Disponible en: <http://www.bvs.ins. gob.pe/insprint/salud_publica/nor_tec/37.pdf>

18. Realpe M, Muñoz A, Chavez J. Manual de procedimientos para la identificación de Escherichia coli 0157:H7 a partir de materia fecal. 2011:1-11.

19. Realpe M. Manual de procedimientos para el diagnóstico bacteriológico de enfermedad diarreica bacteriana aguda, identificación de Salmonella spp., Shigella sp., y Vibrio cholerae. 2011:1-90.

20. Alarcón R, Li J. Serotipificación de Escherichia coli enteropatógena (EPEC) en cuadros diarreicos agudos de niños menores de cinco años: Hospital Nacional Docente MadreNiño San Bartolomé, noviembre 2000-marzo 2001. 2007
Disponible en: <http://cybertesis.unmsm.edu.pe/bitstream/ cybertesis/2941/1/Larcon_br.pdf>

21. Instituto Nacional de Enfermedades Infecciosas. manual de procedimientos campylobacter Ministerio de Salud. 2001. 1-29.

22. Ford-jones A, Cogswell, J. Tests for occult blood in stools of children. Arch. Dis. Child. 1975;50(3):238-40.

23. Guiraldes E. Comparacion entre diversos metodos para diagnóstico rápido de malabsorcion de hidratos de carbono. 1975; 45(5): 395-7.

24. Ghosh S, Littlewood J, Goddard D, Steel A. Stool microscopy in screening for steatorrhoea. J. clin. Path. 1977;30(8):749-53.

25. Boschi-Pinto C, Lanata C, Black R. The Global Burden of Childhood Diarrhoea', in: Ehiri, J.E., M. Meremikwu (editors), International Maternal and Child Health, 2009.

26. Giugno S, Oderiz S. Etiología bacteriana de la diarrea aguda en pacientes pediátricos. Acta bioquímica clínica Latinoam.2010;44(1): 63-70.

27. Giugno S, Oderiz S. Etiología bacteriana de la diarrea aguda en pacientes pediátricos* Bacterial etiology of acute diarrhea in pediatric patients. Acta Bioquím Clín Latinoam 44, 63-9 (2010).

28. Carreazo N, Ugarte K, Huicho L. Leucocitos Fecales en Niños con Diarrea Aguda: ¿Momento de Reconsiderar la Utilidad Clínica de la Prueba?. Revista de Gastroenterologia del Perú. 2011;31(3), 216-23.

29. Ochoa T, Contreras C. Enteropathogenic E. coli (EPEC) infection in children. Curr Opin Infect Dis.2011; 24(5):478-83.

30. Bucher A, Rivara G, Briceño D, Huicho L.Uso de una Prueba Rápida de Rotavirus en la Prescripción de Antibióticos en Diarrea Aguda Pediátrica: Un Estudio Observacional, Aleatorizado y Controlado. Rev. Gastroenterol. Perú. 2012:32(1), 11-5.

31. Alvarado-Rios L, Castillo-Aguilar W. Gastroenteritis por norovirus en Lima. Norovirus gastroenteritis in Lima. Rev Med Hered. Rev Med Hered. 2012;23(1), 136-7.

Fuentes de financiamiento:

Este artículo ha sido financiado por los autores.

Conflictos de interés:

Los autores declaran no tener ningún conflicto de interés.

\section{Correspondencia:}

Heber Silva-Díaz

Dirección: Dirección de Investigación del Hospital Regional Lambayeque. Av. Vía de Evitamiento Norte con Av. El Progreso.

Chiclayo, Perú.

Télefono: 3652300 Anexo 182

Correo electrónico: h.silvadiaz@hotmail.com, hsilva@hrlamb.gob.pe 